\title{
STUDY OF THE RELAXING EFFECT OF SLOW-DYNAMIC GYMNASTIC EXERCISES
}

\section{Vladimir Angelov}

National Sports Academy „Vassil Levski”, Sofia, Bulgaria

\begin{abstract}
Introduction: The relaxation is a psychophysiological state of a person and in particular of athletes. On the basis of the literature sources, two main types of relaxation can be defined-physical and mental. Physical relaxation can be employed to reduce muscular tension and to improve coordination during the performance. It can be suggested that this psychophysiological state creates appropriate conditions for the development of flexibility, speed and all psychomotor qualities. That's why an alternative new means with relaxing effect in this study will be investigated.

Aim: The aim of the study is to prove that the slow-dynamic gymnastic exercises practice leads to reduction of muscular tension. According to the hypothesis of the research, the application of the mentioned exercises will increase the performers'sense of relaxation. The object of the study is a specialized set of gymnastic exercises which includes dynamic gymnastic exercises performed with slow movements and holding of static poses.

Methods: The assessment of the relaxation degree was made through physiological and psychological parameters. The collected physiological data included heart rate, breathing frequency, blood pressure, and finger skin temperature measurement. The psychological data were assessed with Spielberger State Anxiety Inventory and four-point Likert type scale for self-rated relaxation. The measurements were made before and after the execution of the exercises.

Results: Statistically significant changes were found for all variables studied, except systolic blood pressure. The comparison of the collected data from the two measurements showed the greatest differences in three indicators after the application of slow-dynamic gymnastic exercises - a decrease in the Spielberger Inventory results (-7.3 points, $p<0.05)$, a decrease in the heart rate $(-6 \mathrm{bpm}, p<0.05)$ and an increase in the finger skin temperature of both hands (left: $3.5^{\circ}$, right: $\left.3.8^{\circ}, p<0.05\right)$.

Conclusion: In conclusion, the established results confirm the hypothesis of the study and prove the relaxing effect of the slow-dynamic gymnastic exercises.
\end{abstract}

Key words: relaxation degree, types of relaxation, psychophysiological reactions, relaxation techniques, and specialized set of gymnastic exercises

\section{INTRODUCTION}

This article presents the results from a pilot research on the effect of the application of a specialized set of slow-dynamic gymnastic exercises. The main aim of the study is proving the relaxing effect of a distinct type of gymnastic exercises. On this basis, the following questions require an answer: what is the nature of relaxation and its role in sports practice, types of relaxation, ways to achieve the relaxing effect, physiological and psychological reactions of relaxation, benefits of relaxation, and methods for assessment of the level of relaxation.

The literature review allows concluding that relaxation is a psychophysiological state of a person and in particular of athletes. Fur- 
thermore, relaxation is a psycho-physiological process which is based on an individually different reference point on a continuum between activation and deactivation (Vaitl, 2014; Weinberg \& Gould, 2011). It consists of physiological reactions which are an inherent part of human behavior. In other studies, relaxation was defined as a psychological strategy used by sports performers to help manage or reduce stress-related emotions and physical symptoms during high pressurized situations (Iresearchnet.com).

On the basis of the review of the literature sources, two main types of relaxation can be defended - physical and mental. Physical relaxation can be employed to reduce muscular tension and to improve coordination during the performance. It can be achieved by a variety of relaxation techniques such as breathing exercises, progressive muscular relaxation (PMR), and biofeedback (BFB). The mental relaxation focuses primarily on reducing negative emotions such as anxiety. Mental relaxation techniques include transcendental meditation, mindfulness meditation, and autogenic training. Thus, the main structural groups of relaxation techniques are summarized (Figure 1). It was established in research that relaxation led to distinctive longterm effects and it was more than a symptom reduction (Smith, 1999). Previous studies suggested that the greatest effects of relaxation techniques could be expected when a symptom precisely matched the specific goal of the technique (e.g., Davidson \& Schwartz, 1976). Despite the fact that each relaxation technique has its own peculiarities, there are three principles common to all methods: (a) lowering of muscle tone, (b) focusing on the present moment and on body sensations, and (c) relaxing breathing (Hazlett Stevens, 2008). There are a lot of surveys indicating that relaxation techniques benefit athletes by enhancing self-confidence, concentration, performance, reducing anxiety and stress, blood pressure as well as muscle tension. All the different relaxation techniques potentially lead to a variety of psychological and physiological changes which are summarized under the umbrella term relaxation response.

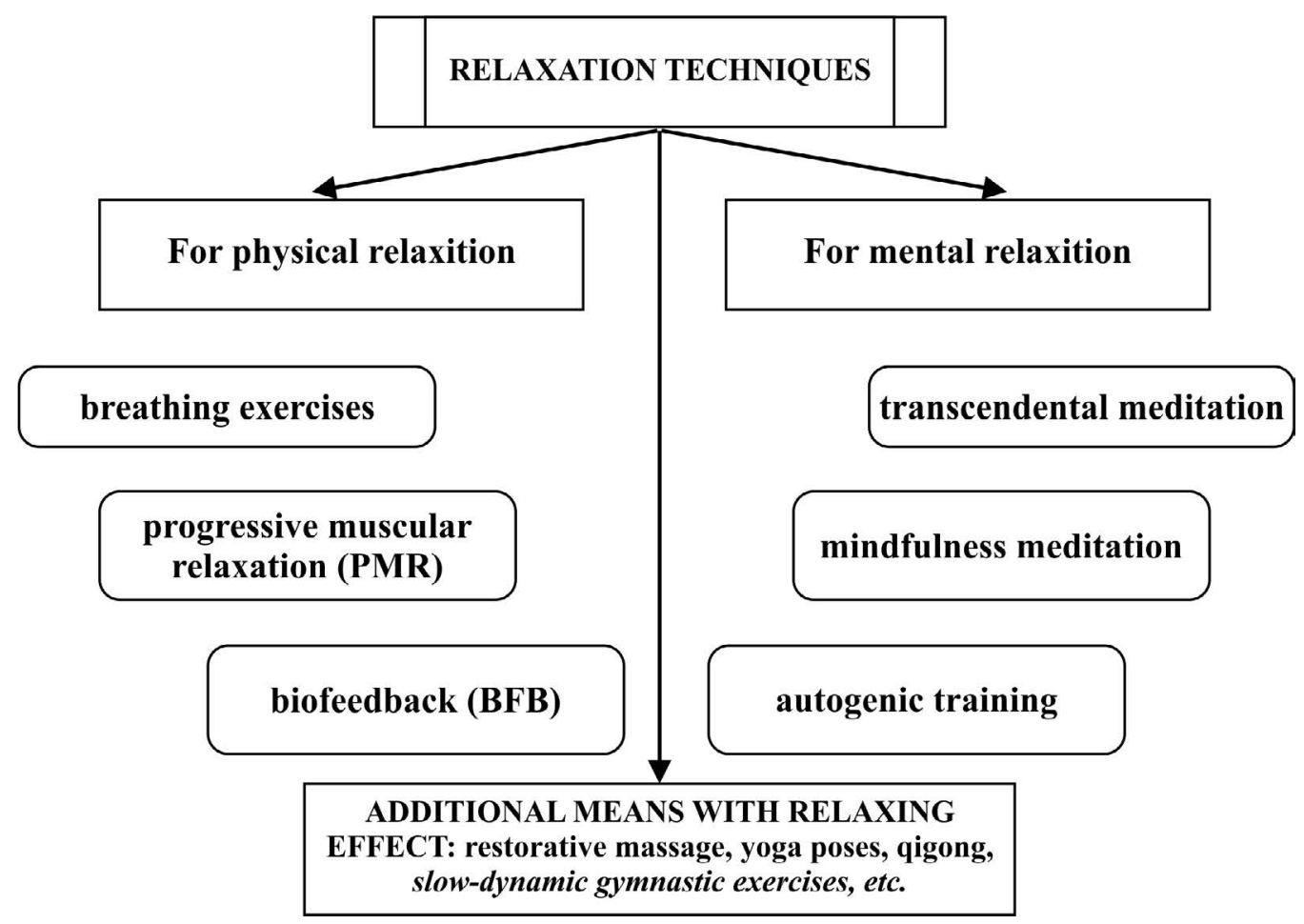

Figure 1. Classification of the relaxation techniques 
The examination of the physiological and psychological reactions of the body is a basic approach to determining the relaxation degree. The relaxation response includes a variety of possible psychological and physiological changes (Andreassi, 2007). On a psychological base, the relaxation response includes an increase in the ability to focus, an increase in well-being, a reduction of anger and arousal, a decrease in lack of activation, a possible increase in self-confidence, the establishment of an inner balance, and a possible prevention of insomnia (Smith, 1999). Strategies with predominant cognitive components were associated with decreases in the level of uneasiness, self-assessment of anxiety or pain, and an increase in the ability to concentrate (Jain et al., 2007). Different versions of PMR, biofeedback, yoga, and systematic breathing are the most investigated techniques in this domain (Kudlackova et al., 2013). Progressive muscle relaxation and its derivations have received the most attention in a scientific context.

Further, biofeedback provides the individual with information about bio-signals which are generated by physiological processes in the body and are generally inaccessible to the conscious perception (Lehrer, 2012). The progressive relaxation training-PRT, developed by Edmund Jacobson in 1929, noted that mental relaxation resulted from body relaxation (Chevallon, 1995). Similarly, systematic breathing (including relaxed basal breathing, diaphragmatic breathing, and abdominal breathing) was reported to be one of the simplest and most effective ways to control anxiety and muscle tension (Lewis et al., 2007). A study by Janet Ortiz (2006) showed that PMR led to improved putting performance among female golfers, while many other sports showed tremendous improvements following the use of PMR and other breath- ing techniques. Some theories underline that applied relaxation derives from behavioral psychology. A pilot study by Catharina Gustavsson and Lena von Koch found that the applied relaxation helped better perceived control over pain and stress among individuals with long-lasting neck pain. (Gustavsson, von Koch, 2006).

Other important aspects of the successful development of relaxation and psyching-up skills are: appropriately structured mental training sessions, reinforcement of the athletes' autonomy, and effective integration of psycho-physiological techniques into sports practice (Pineschi, 2010). For successful development of relaxation and psyching-up skills, three stages of a mental training program are required: (a) "learning stage," in which athletes learn different techniques and identify those best suited to their needs; (b) "training stage," in which athletes repeat, adjust, make automatic and integrate the selected techniques into their training and competition routine; and (c) "application stage," in which athletes use the techniques they have learned and practiced in the stressful context of competitions (Pineschi, 2010; Pineschi \& Di Pietro, 2013).

Another key point is the use of relaxation techniques in sports practice. Petermann and Vaitl (2014) reported hypnosis, autogenic training, meditational (eastern) techniques, imagery, progressive muscle relaxation (PMR) and biofeedback as being the standard repertoire of techniques which are known to induce relaxation. Following Kudlackova et al. (2013), autogenic training, eastern relaxation, and progressive muscle relaxation were the less used techniques compared to deep breathing, meditation and imagery in a study investigating the use of relaxation techniques in professional and semi-professional sports.

The way of assessment of the relaxation 
degree is the next important point. The review of the studies on relaxation and its application showed the importance of this psycho-physiological state in sport. The literature review shows that specialists have explored different approaches and methods for assessment of the psycho-physiological states. Some scientists aimed to determine the effectiveness of the muscle relaxation program in reducing anxiety and to create an action strategy dealing with and alleviating anxiety by using the Competitive Sport Anxiety Inventory and a training program for the progressive muscle relaxation (Ali, 2015). In another study the authors recorded the physiological and psychological responses to the preferred relaxing music by collecting information about vascular constriction, heart rate, muscle tension, finger skin temperature and self-rated relaxation with the Spielberger State Anxiety Inventory and a seven-point Likert type scale. Results indicated that state anxiety decreased and relaxation increased from pre to post-test conditions consistently across trials (Davis, Thaut, 1989). Brown and Fletcher (2017) examined the effects of psychological and psychosocial interventions on sport performance systematically with a meta-analytical but more general approach, revealing that sports performance could benefit from the implementation of those interventions. Contrary to these findings, in their review on stress management techniques (incl. relaxation techniques), Rumbold et al. (2012) reported that evidence regarding the intervention-performance relationship appeared to be weak. They found that stress management interventions were effective in terms of reducing stressors, modifying cognitive appraisals, reducing negative affect states, increasing positive affect states, and facilitating effective coping behavior but only had little to no impact on performance.

In some of the reviewed literature sources, the authors established the relaxation degree achieved through application of recovering massage therapy with the help of different indicators such as evaluation of trunk flexion, heart rate, heart rate variability, blood pressure, cortisol level, mood, state anxiety, muscular tension, intensity and pressure threshold of the musculoskeletal pain, and body flexibility (Leivadi et al., 1999; Hasson et al., 2004; Nordschow, Bierman, 1962; Moyer et al., 2004; Braun et al., 2012; Buttagat et al., 2011; Angelov et al., 2016).

The literature review allows generalizing the relaxation as a problem of sports theory and practice where the attention of sports specialists is focused. It can be concluded that the nature of relaxation, the forms of relaxation, the effects of the application of various relaxation techniques and the methods of assessing the relaxation degree have been examined by a number of experts. Nevertheless, supplementing sports theory and methodology with new facts about how to achieve and implement the relaxation in sport practice will help to improve training programs and to increase athletes' opportunities.

Therefore, the main idea of this research was to investigate the new alternative means that lead to relaxing effect. The purpose of the study was to prove that the slow-dynamic gymnastic exercises practice leads to reduction of muscular tension. According to the hypothesis of the research, the application of the mentioned types of exercises will increase the performers' relaxation. It is important to emphasize that the relaxing effect of the new impact is not the only effect that is aimed by the application of the specialized gymnastic sets. Another aspect of the slow-dynamic gymnastic exercises designation, that is not object of this study, is increasing the body working capacity through low-intensity exercises and less energy expenditure. It can be suggested 
that the additional relaxing effect provides the necessary and appropriate conditions for development of flexibility, speed, coordination, and other psychomotor qualities.

\section{METHODS}

\section{Participants}

The research was done among 35 Bulgarian athletes (5 women and 30 men) aged between 18 and 25 years $(21.2 \pm 2.2$ years $)$ who practice acrobatic and trampoline gymnastics. The athletes fulfilled the following criteria: a background of systematic training, continuous training for the previous 3 months with the absence of musculoskeletal injury, absence of potential medical problems that could compromise the participation or performance in the study. Participants were informed about the experimental design of the study.

\section{Experimental Design}

The set includes dynamic gymnastic exercises that are performed with slow movements with influence on the whole body. The impact of this gymnastic set is implemented through movements and poses that include all types of muscle contractions: isotonic, isometric, concentric and eccentric. The gymnastic set of exercises used in this study was built on the basis of several principles: a) after doing exercises for certain muscle groups, some motions for antagonist muscles activation are performed; b) including exercises that have a pronounced effect on joints' receptors which distinguishes this type of gymnastics exercises from the standard ones; c) keeping a specific body posture during the performance of the exercises as an important prerequisite for achieving the desired effect. The basic position of the body is the upright position of the spine; d) emphasizing the voluntary relaxation of the muscles during the performance of the exercises. One should train for a prop- er body posture and develop self-relaxation skills during the performance of the exercises to achieve a greater effect.

The duration of the gymnastic set is 35 minutes. It includes two parts: a slow-dynamic (30 $\mathrm{min})$ and dynamic $(5 \mathrm{~min})$ one. The slow-dynamic part consists of 26 exercises with total influence. Each exercise is repeated twice in both directions - left and right. The dynamic part consists of 12 exercises for legs joints and swing movements with the lower limbs that are repeated 9 times with both legs. It is important to note that the performance of the exercises does not require maximum amplitude and intensity. The movements' amplitude and intensity have to depend on the momentary physiological state of the athletes.

Both the instructor and the participants do the set of slow-dynamic gymnastic exercises after the instructor shows how to perform them. This helps the participants to eliminate the unnecessary tension associated with memorizing the sequence of the exercises and to pay more attention to the correct performance.

\section{Measure Procedure}

The study was conducted in two types of conditions. The first condition included initial registration of the physiological and psychological indicators at rest. The second condition contained a measurement of the same parameters after the performance of the gymnastic set of slow-dynamic exercises.

The assessment of the relaxation degree was made through two parameters groups: physiological and psychological. Physiological data collected included: heart rate (bpm), respiratory rate (breaths per minute), blood pressure $(\mathrm{mm} \mathrm{Hg})$, and finger skin temperature $\left({ }^{\circ} \mathrm{C}\right)$. The heart rate (HR), systolic blood pressure (SBP), and diastolic blood pressure (DBP) were measured with the help of blood pressure monitor TRANSTEK TMB-1491-A. 
A chronometer MAS-JS-9003 model, maker JUNSO for respiratory rate (RR) measuring was used. The temperature of the middle fingertip on the left and right hand was measured with infrared thermometer with laser targeting. The measurement of the mentioned physiological indicators was manually accomplished in equal conditions: ambient temperature $-20-23^{\circ}$, normal humidity, each participant in lying position, a skillful examiner. The psychological data were assessed with the Spielberger State Anxiety Inventory and a four-point Likert type scale for a selfrated state of relaxation. The duration of the research was one month.

\section{Data and Statistical Analysis}

The collected data from the study were statistically processed with the statistics package SPSS 17.0. The data were descriptively analyzed (mean \pm standard deviation). Shapiro-Wilk (SW) test to determine the normality of data distribution was used. Student's paired t-test for normal data distribution and
Wilcoxon test for non-normal data distribution to find the differences in the variables studied were used. The level of significance $p \leq 0.05$ was adopted in all cases. In addition, an effect size was calculated. According to the descriptors of magnitudes of the effect size, as initially suggested by Cohen (1988) and expanded by Sawilowsky (2009), the following six degrees of this indicator can be defined: very small (0.01), small (0.2), medium (0.5), large (0.8), very large (1.2), and huge (2).

\section{RESULTS}

The values of the physiological and psychological parameters studied before and after the specialized gymnastic set of exercises are summarized in Table 1. The HR and diastolic BP results were with normal distribution. All the rest indicators studied were with an abnormal data distribution. The results were statistically significant, except the values of the systolic blood pressure.

Table 1. Results from the descriptive analysis (mean $\pm S D$ ).

\begin{tabular}{llll}
\hline $\begin{array}{l}\text { Parameters } \\
\text { studied }\end{array}$ & $\begin{array}{l}\text { Initial } \\
\text { measurement }\end{array}$ & $\begin{array}{l}\text { Final } \\
\text { measurement }\end{array}$ & p-values \\
\hline $\begin{array}{l}\text { Heart rate (bpm) } \\
\text { Respiratory rate } \\
\text { (breaths per minute) }\end{array}$ & $79.1 \pm 7.1$ & $73.1 \pm 7.2$ & $<0.05$ \\
$\begin{array}{l}\text { Systolic blood pressure } \\
\text { (mm Hg) }\end{array}$ & $14.9 \pm 3.1$ & $14.1 \pm 2.5$ & $<0.05$ \\
$\begin{array}{l}\text { Diastolic blood pressure } \\
\text { (mm Hg) }\end{array}$ & $120.2 \pm 8.0$ & $119.9 \pm 5.0$ & $>0.05$ \\
$\begin{array}{l}\text { Finger skin temperature } \\
\text { Left }\left({ }^{\circ} \mathrm{C}\right)\end{array}$ & $75.1 \pm 5.5$ & $77.3 \pm 3.5$ & $<0.05$ \\
$\begin{array}{l}\text { Finger skin temperature } \\
\text { Right }\left({ }^{\circ} \mathrm{C}\right)\end{array}$ & $26.9 \pm 4.8$ & $30.4 \pm 5.0$ & $<0.05$ \\
$\begin{array}{l}\text { Spielberger State Anxiety } \\
\text { Inventory (points) }\end{array}$ & $32.1 \pm 8.1$ & $30.8 \pm 4.2$ & $<0.05$ \\
\hline
\end{tabular}

The effect size calculated as a result of the exercises is presented in Figure 2. application of the slow-dynamic gymnastic 


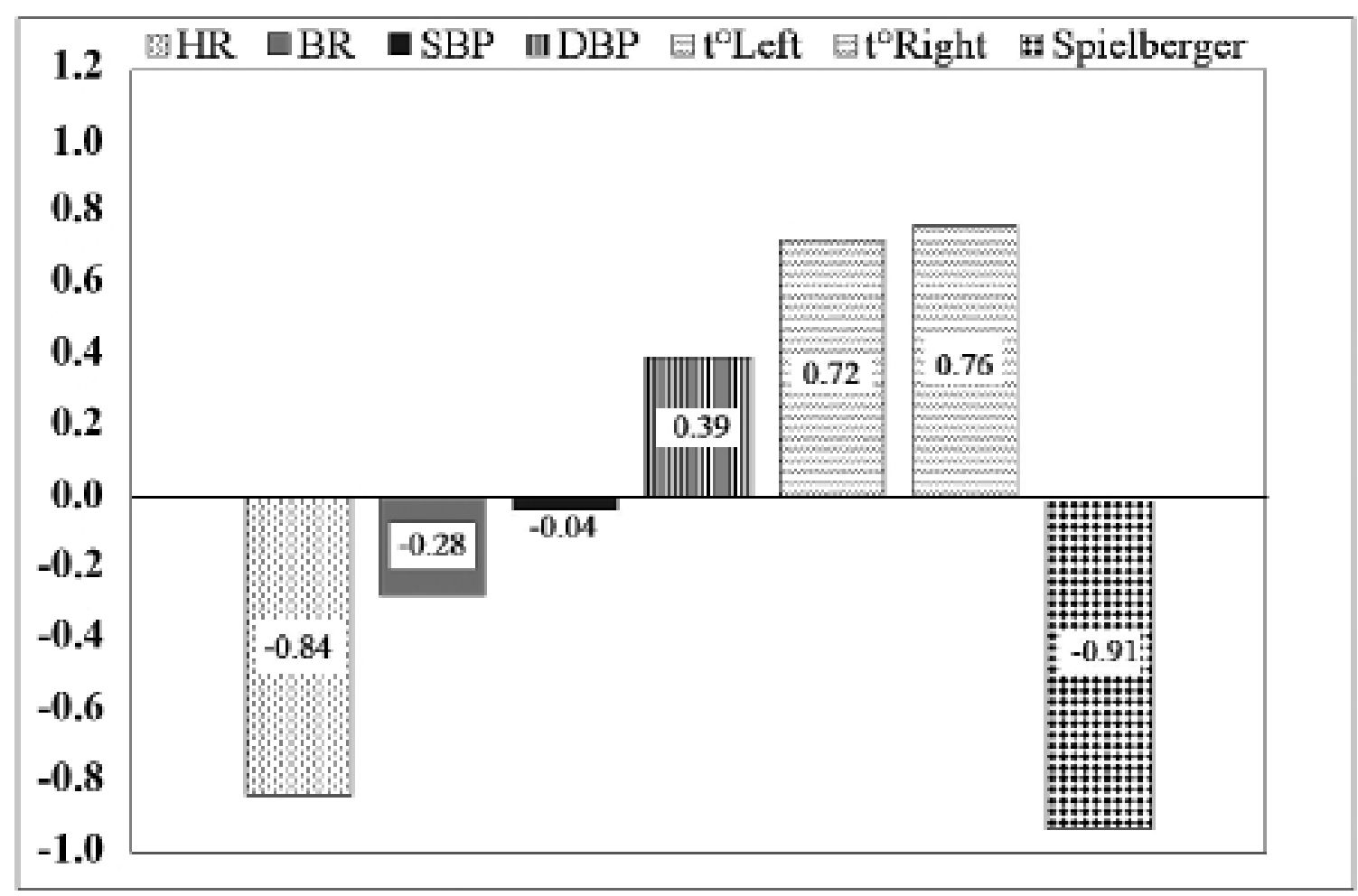

Figure 2. Effect sizes of the parameters studied: heart rate, breathing rate, systolic and diastolic blood pressure, fingertip skin temperature of both hands, and Spielberger State Anxiety Inventory.

The heart rate before $(79.1 \pm 7.1 \mathrm{bpm})$ and after $(73.1 \pm 7.2 \mathrm{bpm})$ the set of slow-dynamic gymnastic exercises performance was one of the main parameters used to prove the relaxing effect. For confirming the hypothesis of the study, the statistically significant difference between the initial and the final HR after the new impact was established ( $-6 \mathrm{bpm} ; p<0.05)$. The value of this indicator was decreased with $6 \mathrm{bpm}$ as a result of slow-dynamic exercises performance. The effect size of the established heart rate was -0.84 . On the basis of the described effect size degrees, the heart rate effect size was large.

Next, a statistically significant difference between the initial and the final respiratory rate was established $(-0.8$ breaths per minute; $p<0.05)$ to define the result of the new impact. The mean value from the initial measurement was $14.9 \pm 3.1$ breaths per minute, and the value from the final measurement was $14.1 \pm 2.5$. The effect size of the breathing frequency calculated $(-0.28)$ shows a small degree of this indicator.
A comparison of the established mean values of the blood pressure was made. The results obtained were statistically insignificant for the systolic BP and statistically significant for the diastolic BP. The systolic blood pressure data show that the mean values before the gymnastic set performance was $120.2 \pm 8.0 \mathrm{mmHg}$ and after the slow-dynamic exercises was $119.9 \pm$ $5.0 \mathrm{mmHg}$. A low difference between the initial and final measure procedure was established. The decrease in this indicator after the application of the specialized gymnastic complex was small (SBP: $-0.3 \mathrm{mmHg}, p>0.05$ ). The effect size calculated was very small $(-0.04)$. These facts allow making a conclusion for the lack of effect of the new impact on the systolic blood pressure. The mean value of the diastolic blood pressure from the initial measurement was 75.1 $\pm 5.5 \mathrm{mmHg}$, and the value from the final measurement was $77.3 \pm 3.5 \mathrm{mmHg}$. The data collected for this indicator showed an increase in the values with $2.2 \mathrm{mmHg}(p<0.05)$ as a result 
of slow-dynamic gymnastic exercises performance. The medium degree of the effect size for this parameter was calculated (0.39). It is obvious that the new impact causes greater changes in diastolic blood pressure.

A statistically significant difference in the registered finger skin temperature before and after the new impact was found. The measuring of this parameter in the two conditions of the study showed similar results between the temperature of the left and right finger. The initial values recorded were $26.9 \pm 4.8^{\circ}$ for the left and $27.0 \pm$ $4.5^{\circ}$ for the right hand. The values established after the new impact were respectively $30.4 \pm$ $5.0^{\circ}$ and $30.8 \pm 4.2^{\circ}$ for the left and right finger. An increase of this parameter after the slow-dynamic gymnastic exercises performance was established (left finger: $3.5^{\circ}, p<0.05$; right finger: $\left.3.8^{\circ}, p<0.05\right)$. The effect size degree was large (left finger: 0.72; right finger: 0.76).

Next, the collected data from the Spielberger State Anxiety Inventory was analyzed with the help of a four-point Likert type scale for self-rated relaxation (Table 1 and Figure 2). The results obtained on the basis of the subjective sensations before and after the new impact were statistically significant. The analysis of the answers from the self-assessment questionary on the state anxiety shows that before the new impact, the average value of this indicator was $32.1 \pm 8.1$ points, and after the performance of the specialized set of gymnastic exercises it decreased to $24.8 \pm 5.8$ points. The difference between the initial and the final state anxiety was established (-7.3 points; $p<0.05)$. A very large effect size was calculated $(-0.91)$.

\section{DISCUSSION}

The key findings of this study were in regard to the positive physiological and psychological effects from the execution of slow-dynamic gymnastic set of exercises. On this basis, the main task was to prove the effectiveness of the new impact on the physical relaxation stimulation and the decrease in state stress. Additionally, we can suggest that the application of this type of exercises leads to enhancing the regulatory capacity of the nervous system, improving the peripheral blood circulation, stimulating the recovery processes, improving the working capacity and functioning of the locomotor system. In this study, the focus is on proving the relaxing effect of the slow-dynamic gymnastic exercises.

The realization of the main task of this study was implemented through the functional measuring of heart rate, respiratory rate, blood pressure, finger skin temperature, and state anxiety as indicators for determining the relaxation degree. The literature review showed that the heart rate is a widely used parameter for assessing the physiological response of the body and mind as a result of different types of influences. The research approach in this article has a certain similarity to an idea of the reviewed study, which aimed to investigate possible effects of mechanical massage and mental training through heart rate, blood pressure and fingertip temperature measurement (Muller et al., 2016). Another argument in favor of the chosen indicators for the assessment of the relaxation level was their easily and timely application. The results obtained were processed and analyzed quickly and easily. It is known that the heart rate depends on various external factors. Nevertheless, the application of this indicator is appropriate for comparison of initial and final physiological state - before and after the performance of specialized gymnastic set of exercises. State Anxiety Spielberger Inventory was chosen to assess the subjective aspect of the relaxation degree because of its easy and rapid applicability. In future studies, additional psychological methodologies to assess the subjective sensations of the participants in regard to the relaxation degree will be used. A study examined in the literature review sparks an interest by adapting 
methods for collecting such kind of data in sport (Iancheva, Yordanov, 2011).

The results from the two conditions of the study were analyzed. It was expected that the relaxing effect of the new impact would be established.

The recorded heart rate delay was expected because the application of the slow-dynamic gymnastic exercises activates the parasympathetic nervous system. Similar results were obtained after the application of massage therapy which are described in some of the studies cited in the literature review (Braun et al., 2012; Kaye et al., 2008; Chompoopan, Eungpinichpong, 2016; Pinar, Afsar, 2015; Pystupa, 2013; Supa'at et al., 2013; Muller et al., 2016; Paschoala, 2016). It can be summarized that the issue of reliability of the heart rate as an indicator for assessment of the psychosomatic states can be discussed as it depends on many external factors. In this connection, in similar future research, the method of the variability of the heart rate will be used.

The lower respiratory rate recorded after the execution of the specialized gymnastic set of exercises can be viewed as a positive result even though the difference established is less than one breathing cycle and the effect size is small. All of the above mentioned respiratory rate results are not impressive but they indicate the existence of a relaxing effect after the application of slowdynamic exercises.

An interesting fact is that some participants' values of the blood pressure from the initial measurement deviated from the norm, whereas after the performance of the complex of slowdynamic gymnastic exercises these values were normal. For this reason, the effect of the new impact on the blood pressure will be investigated in further studies with larger and more diverse samples. It is possible that the reason for the small change in the results of the commented respiratory rate and systolic blood pressure before and after the new impact is its duration. We suppose that if the duration of the set of slow-dynamic gymnastic exercises is longer, the difference between the two parameters in the two conditions of the study could be bigger. In this connection, it is logical to assume that the extended impact time will also increase the effect on the other examined indicators. It can be concluded that respiratory rate and systolic blood pressure are parameters less influenced by the application of the slow-dynamic gymnastic exercises.

We can conclude that the established results of the fingertip skin temperature are in favor of the new impact. It is obvious that the slowdynamic gymnastic exercises performance leads to an increase in the finger skin temperature of both arms. This means that peripheral blood circulation is improved. On this basis, it can be concluded that the relaxation degree has also increased. Another interesting point about this indicator is the established results of asymmetry between the finger skin temperature of the left and right hand, which after the application of the new impact, not only increased but also became symmetrical in relation to both hands. This issue deserves more attention and it will be explored in future studies.

The positive result of the Spielberger State Anxiety Inventory can be determined as unexpected. The greatest effect size for this psychological indicator in comparison with the other parameters studied was calculated. The psychological data also confirmed that the slow-dynamic gymnastic exercises performance leads to a relaxing effect and reduces state anxiety.

The analysis of the collected data did not include a study of the relation between the results of the men and the women. This will be done in future research with more female participants.

This study found that slow-dynamic gymnastic exercises have a relaxing effect. Furthermore, the performance of these exercises can be used as a means of influence on the two types of relaxation - physical and mental. The decrease 
in the heart rate mean values and the increase in the fingers skin temperature after application of slow-dynamic exercises proves the achievement of physical relaxation. The results of the self-assessment survey on the relaxation degree confirm the presence of mental relaxation. In this connection, it is important to emphasize the essence and the role of the relaxation in sport. Other studies indicated that the most successful athletes used more relaxation techniques compared to the less successful ones (Gould, Eklund \& Jackson, 1993; Orlick \& Partington, 1988).

The relaxing effect established from the slow-dynamic gymnastic exercises performance is a prerequisite for this set of exercises to be used as therapeutic support. Some relaxation techniques mentioned in the literature review were utilized as therapeutic support in the treatment of psychological and physiological disorders. All these relaxation techniques can be defined as a means through which individuals are able to reduce their muscle and psychological tension voluntarily.

The slow-dynamic gymnastics exercises utilized in the study can be defined as a muscularly-oriented method for relaxation. In this sense, Davidson and Schwartz' matching hypothesis (1976), Kudlackova et al.'s study (2013), and Lehrer (1996) all suggest that muscularly-oriented methods have the greatest effects on the musculoskeletal system and autonomically-oriented methods on the autonomic nervous system.

Next, the slow-dynamic gymnastic exercises performance can be characterized as a method based on the training of self-perception of the muscular sensations and aimed to reduce the muscle tension. As such a method, it generates a great effect on the psychosomatic processes management. Following the theory of Jacobsen (1938), the central aim of a relaxation technique is the deliberate and continuous reduction of tension in specific muscle groups of the locomotor system. The original method in which the emphasis is on the training of self-perception of muscular sensations has greater effects on somatic issues while the revised versions in which producing a subjective experience of relaxation is the key strategy, have a greater impact on cognitive symptoms (Fears and anxieties; Dolbier \& Rush, 2012).

Previous research divided the relaxation techniques into two separate paths (Davidson \& Schwartz, 1976; Kenttä \& Hassmén, 1998). Muscle-to-mind techniques focus on the training of one's sensitivity to muscle tension (e.g., PMR, breathing techniques) while mind-to-muscle techniques focus on the cognitive processes involved in relaxation (e.g., autogenic training, hypnosis). The slow-dynamic gymnastic exercises in such classification of the relaxation techniques belong to the group of muscle-tomind techniques. Furthermore, the new impact creates more opportunities to achieve relaxation and to increase the ability to manage the psychophysiological states of the athletes. The relaxing effect of the new impact established in this study is mainly used to influence the locomotor system and to improve working capacity. It is an appropriate condition for developing flexibility, speed, and coordination. Hence, the logical question is how the speed can be achieved by applying relaxation techniques. The answer is that such type of impact increases the conduction of the nerve impulses of the athletes. This indirectly leads to improvement of the speed.

On the basis of the physiological and psychological data collected in this study, the slowdynamic gymnastic exercises can be defined as a somatic-based relaxation technique with an additional positive effect on mental relaxation. In this sense, Davidson and Schwartz's (1976) matching hypothesis states that somatic-based relaxation has greater effects in reducing somatic stress while cognitive-based techniques reduce anxiety or cognitive stress.

At the end of the discussion, it can be summa- 
rized that the slow-dynamic gymnastic exercises examined in this study have the following characteristics: a) have a relaxing effect - physical and mental; b) can be defined as a muscularlyoriented method for relaxation based on training of self-perception of the muscular sensations; c) aim to reduce the muscle tension; d) can be used as therapeutic support; e) belong to the group of muscle-to-mind techniques and to the group of somatic-based relaxation techniques.

The study is limited by factors such as age, education, social and health status, sports qualification, and the size of the sample. Furthermore, as an additional limit, the indicators studied can be defined. This study is a part of a project that aims to elaborate a complex methodology for the assessment of the psychophysiological characteristics of the motor actions. This means that in further research of this nature, more methods to estimate the psychophysiological states will be included.

\section{CONCLUSION}

The results obtained confirmed that the hypothesis of the study is correct. This allowed concluding that the application of slow-dynamic gymnastic exercises in the training process can be used to reduce the muscle tension and to decrease the state anxiety. It is important to emphasize that physical relaxation was suggested as a result of the new impact, while the positive effect on state anxiety was unexpected. This type of exercises allows the successful management of psychosomatic processes. On this basis, this influence can be defined as an additional relaxation technique. Furthermore, the new impact has many other positive effects that will be investigated and proven in future studies. The slowdynamic gymnastic exercises can be used as a means for improvement of the working capacity of the locomotor system, as an alternative means for warming up, as an appropriate way for stimulating the recovery, as a means for protection against injuries, as a means creating appropriate conditions for development of flexibility, speed, coordination, and other psychomotor qualities.

\section{REFERENCES}

Ali, K. (2015). The Effectiveness of Progressive Muscle Relaxation to Reduce the Intensity of Competitive Sport Anxiety among the Elite Players Football. Res. J. Physical Education Sci. Vol. 3, No. 2, pp. 4-8.

Andreassi, J. L. (2007). Psychophysiology: Human Behavior and Physiological Response. Publisher: Lawrence Erlbaum, New York.

Angelov, V., Gotova J, Albert, E., Tishinov, O. (2019). Application of the Visualization through Stereoscopic Glasses in the Massage Therapy. Exercise Medicine, Vol. 3, No. 2, pp. 1-7.

Braun, L.A., Stanguts, C., Casanelia, L., Spitzer, O., Paul, E., Vardaxis, N.J., Rosenfeldt, F. (2012). Massage therapy for cardiac surgery patients - a randomized trial. J Thorac Cardiovasc Surg. Vol. 144, No. 6, pp. 1453-1459.

Brefczynski-Lewis, J. A., Lutz A., Schaefer H. S., Levinson D. B., Davidson R. J. (2007). Neural correlates of attentional expertise in long-term meditation practitioners. PNAS, Vol. 104, No. 27, pp. 11483-11488.

Brown, D. J., Fletcher, D. (2017). Effects of Psychological and Psychosocial Interventions on Sport Performance: A Meta-Analysis. Sports Med. Vol. 47, pp. 77-99.

Buttagat, Vitsarut \& Eungpinichpong, Wichai \& Chatchawan, Uraiwan \& Kharmwan, Samerduen. (2011). The Immediate Effects of Traditional Thai Massage on Heart Rate Variability and Stress-Related Parameters in Patients with Back Pain Associated with Myofascial Trigger Points. J Bodyw Mov Ther., Vol. 15, pp. 15-23.

Chevallon, S. (1995). L'entraînement psychologique du sportif [Mental training for athletes]. Editions De Vecchi, Paris, France.

Chompoopan, W., Eungpinichpong, W. (2016). Effects of Traditional Thai Massage on Heart Rate, Blood Pressure, and Anxiety in Depression Patients: A Pilot Study. Int J Geom. Vol. 
11, No. 28, pp. 2892-2895.

Cohen, J. (1988). Statistical power analysis for the behavioral sciences (2nd ed.). Hillsdale, NJ: Lawrence Erlbaum Associates.

Davidson, R. J., Goleman, D. J., \& Schwartz, G. E. (1976). Attentional and affective concomitants of meditation: A cross-sectional study. Journal of Abnormal Psychology, Vol. 85, No. 2, pp. 235-238.

Davis, W. B., Thaut, M. H. (1989). The Influence of Preferred Relaxing Music on Measures of State Anxiety, Relaxation, and Physiological Responses. Journal of Music Therapy, Vol. 26, No. 4, pp. 168-187.

Dolbier, C. L., Rush, T.E. (2012). Efficacy of Abbreviated Progressive Muscle Relaxation in a High-Stress College Sample. International Journal of Stress Management, Vol. 19, No. 1, pp. 48-68.

Gould, D., Eklund, R., Jackson, S.A. (1993). Coping Strategies Used by U.S. Olympic Wrestlers. Research quarterly for exercise and sport. Vol. 64, No. 1, pp. 83-93.

Gustavsson, C., von Koch, L. (2006). Applied relaxation in the treatment of long-lasting neck pain: A randomized controlled pilot study. J Rehabil Med; Vol. 38, pp. 100-107.

Hasson D., Arnetz B., Jelveus L.A. (2004). Randomized clinical trial of the treatment effects of massage compared to relaxation tape recordings on diffuse long-term pain. Psychother Psychosom. Vol. 73, pp. 17-24.

Hazlett-Stevens, H. (2008). Psychological approaches to generalized anxiety disorder:A clinician's guide to assessment and treatment. NY: Springer, New York.

Iancheva, T., Yordanov, V. (2011). Balgarska adaptacia na Scala za izsledvane na trevojnostta v sporta (Sport Competitive Trait Anxiety - SCAT). Lichnost, motivacia, sport. T. 16, pp. 126-131. //Янчева, Т., В. Йорданов (2011). Българска адаптация на Скала за изследване на тревожността в спорта (Sport Competitive
Trait Anxiety - SCAT). Личност, мотивация, спорт. Т. 16, с. 126-123.

Iresearchnet.com. Relaxation in Sport. Available at: https://psychology.iresearchnet. com/sports-psychology/psychological-skills/ relaxation-in-sport (accessed 15 March 2019).

Jacobson, E. (1938). Progressive Relaxation. IL: University of Chicago Press, Chicago.

Jain S., Shapiro S.L., Swanick S., Roesch S.C., Mills P.J., Bell I., Schwartz G.E. (2007). A randomized controlled trial of mindfulness meditation versus relaxation training: effects on distress, positive states of mind, rumination, and distraction. Ann Behav Med.; Vol. 33, No. 1, pp. 11-21.

Kaye, AD., Kaye, A.J., Swinford, J., Baluch, A., Bawcom, B.A., Lambert, T.J., Hoover, J.M. (2008). The Effect of Deep-Tissue Massage Therapy on Blood Pressure and Heart Rate. J Altern Complement Med. Vol. 14, No. 2, pp. 125-128.

Kenttä G., Hassmén P. (1998). Overtraining and recovery. A conceptual model. Sports Medicine; Vol. 26, No. 1, pp. 1-16.

Kudlackova, K. and Eccles, D. W. and Dieffenbach, K. (2013). Use of relaxation skills in differentially skilled athletes. Psychology of Sport and Exercise; Vol. 14, pp. 468-475.

Leivadi, S., Hernandez-Reif, M., Field, T., O'Rourke, M, D'Arienzo, S., Lewis, D., Pino, N. del, Schanberg, S., Kuhn, C. (1999). Massage therapy and relaxation effects on university dance students. J Dance Med Sci. Vol. 3, No. 3, pp. 108-112.

Moyer, C. A., Rounds, J., Hannum, J.W. (2004). A meta-analysis of massage therapy research. Psychol Bull. Vol. 130, pp. 3-18.

Muller J., EkströmA., Harlén, M., Lindmark, U., Handlina, L. (2016). Mechanical Massage and Mental Training Programs Effect Employees' Heart Rate, Blood Pressure and Fingertip Temperature: An exploratory pilot study. Eur $J$ Integr Med., Vol. 8, No. 5, pp. 762-768. 
Nordschow M., Bierman W. (1962). The influence of manual massage on muscle relaxation: effect on trunk flexion. J Am Phys Ther Assoc. Vol. 42, No. 10, pp. 653-657.

Orlick, T., Partington, J. (1988). Mental Links to Excellence. Sport Psychologist. Vol. 2, No. 2.

Ortiz, J. (2006). Efficacy of relaxation technique in increasing sports performance in women golfers. The Sport Journal, Vol. 20.

Parnabas, V. A., Mahamood Y., Parnabas J., Abdullah, N. M. (2014). The Relationship between Relaxation Techniques and Sport Performance. Universal Journal of Psychology Vol. 2, No. 3, pp. 108-112.

Paschoala, M. A. (2016). Influence of Classic Massage on Cardiac Autonomic Modulation. Fisioter Mov, Vol. 29, No. 3, pp. 487-496.

Pinar, R., Afsar, F. (2015). Back Massage to Decrease State Anxiety, Cortisol Level, Blood Prsessure, Heart Rate and Increase Sleep Quality in Family Caregivers of Patients with Cancer: A Randomised Controlled Trial. Asian Pac J Cancer Prev. Vol. 16 ,No. 18, pp. 8127-8133.

Pineschi, G., Di Pietro, A. (2013). Anxiety Management through Psychophysiological Techniques: Relaxation and Psyching-Up in Sport. Journal of Sport Psychology in Action Vol. 4, No. 3, pp. 181-190.

Pineschi, G. (2010). Mental training and imagery in sport. Olympic Laboratory (Technical scientific bulletin of the Brazilian Olympic Committee). Vol. 15, No 3.
Pystupa, T. D. (2013). Effect of Partial Sports Massage on Blood Pressure and Heart Rate. Phys Ed Stud, Vol. 6, pp. 55-58.

Rumbold, J.L., David Fletcher, D., Daniels, K. (2012). A Systematic Review of Stress Management Interventions with Sport Performers. Sport, Exercise, and Performance Psychology, Vol. 1, No. 3, pp. 173-193.

Sawilowsky, S. S. (2009). New effect size rules of thumb. Journal of Modern Applied Statistical Methods, Vol. 8, No. 2, pp. 597-599.

Smith, E. R. (1999). Affective and cognitive implications of group membership becoming part of the self: New models of prejudice and of the self- concept. In D. Abrams \& M. Hogg (Eds.), Social identity and social cognition pp. 183-196. Oxford: Blackwell Publishers.

Supa'at, I., Zakaria, Z., Maskon, O., Aminuddin, A., Nordin, NA. (2013). Effects of Swedish massage Therapy on Blood Pressure, Heart Rate, and Inflammatory Markers in Hypertensive Women. J Evid Based Complementary Altern Med., pp. 1-8.

Vaitl, D. (2014). Neurobiologische Grundlagen der Entspannungsverfarhen. In F. Petermann, D. Vaitl (Hrsg.), Entspannungsverfahren. Das Praxishandbuch (5., uberarb. Aufl., S. 3551). Weinheim: Beltz.

Weinberg, R. S., Gould, D. (2011). Foundations of sport and exercise psychology, US: Human Kinetics, 5th Edition, Champaign, IL.

\section{Corresponding author:}

Vladimir Angelov

Department of „Gymnastics“

National Sports Academy "Vassil Levski" Studentski grad, 21, Acad. Stefan Mladenov str.

Sofia 1700, Bulgaria

E-mail: angelov.vl@gmail.com 